Tropical Journal of Pharmaceutical Research November 2021; 20 (11): 2261-2266

ISSN: $1596-5996$ (print); 1596-9827 (electronic) (C) Pharmacotherapy Group, Faculty of Pharmacy, University of Benin, Benin City, 300001 Nigeria.

\title{
Octreotide ameliorates hypoxia/reoxygenation-induced cerebral infarction by inhibiting oxidative stress, inflammation and apoptosis, and via inhibition of TLR4/MyD88/NF-KB signaling pathway
}

\author{
Yanbin Hou ${ }^{1}$, Zhongze Lou ${ }^{1}$, Yunxin $\mathrm{Ji}^{1}$, Liemin Ruan ${ }^{1}$, He Gao ${ }^{2 *}$ \\ ${ }^{1}$ Department of Psychosomatics, Ningbo First Hospital, ${ }^{2}$ Department of Psychiatry, Ningbo Kangning Hospital, Ningbo, China
}

*For correspondence: Email: 812478044@qq.com; Tel: +86-015958272157

Sent for review: 27 May 2021

Revised accepted: 3 October 2021

\begin{abstract}
Purpose: To explore the effects of octreotide (OCT) on oxidative stress, inflammation and apoptosis in hypoxia/reoxygenation (H/R)-induced cerebral infarction.

Methods: The in vitro model of cerebral infarction was established by treating N2A cells with hypoxia for $4 h$ and reoxygenation for $24 h$. The viability of N2A cells was determined by CCK-8 assay. The cells were divided into 3 groups: control group, $H / R$ group, and $H / R+O C T$ group. The cells in $H / R+O C T$ group were pretreated with OCT $(60 \mathrm{ng} / \mathrm{mL})$ before H/R treatment. The oxidative stress of N2A cells were assessed by determining the levels of superoxide dismutase (SOD), glutathione peroxidase (GSH$P x)$, catalase (CAT), reactive oxygen species (ROS) and malondialdehyde (MDA). Inflammation of N2A cells was evaluated by evaluating the levels of TNF- $\alpha, I L-1 \beta, I L-6$, and IL-8, while the apoptosis of N2A cells was assessed by flow cytometry. Western blot analysis was used to determine the expression of Bcl-2, Bax, TLR4, MyD88, and NF-KB.

Results: Octreotide treatment significantly reduced the level of oxidative stress. The inflammation of N2A cells caused by hypoxia/reoxygenation was inhibited by treatment with octreotide. Apoptosis of N2A cells was also inhibited by octreotide treatment. Hypoxia/reoxygenation activated TLR4/MyD88/NF$K B$ signaling pathway, while octreotide inhibits the activation of this pathway.

Conclusion: The results reveal that octreotide inhibits hypoxia/reoxygenation-induced oxidative stress, as well as the inflammation, and apoptosis of N2A cells by inhibiting TLR4/MyD88/NF-KB signaling pathway. Thus, these findings may provide new insights into the treatment of cerebral infarction.
\end{abstract}

Keywords: Octreotide, Cerebral infarction, Hypoxia/reoxygenation, Oxidative stress, Inflammation, Apoptosis, TLR4/MyD88/NF-KB signaling pathway

\begin{abstract}
This is an Open Access article that uses a funding model which does not charge readers or their institutions for access and distributed under the terms of the Creative Commons Attribution License (http://creativecommons.org/licenses/by/4.0) and the Budapest Open Access Initiative (http://www.budapestopenaccessinitiative.org/read), which permit unrestricted use, distribution, and reproduction in any medium, provided the original work is properly credited.

Tropical Journal of Pharmaceutical Research is indexed by Science Citation Index (SciSearch), Scopus, International Pharmaceutical Abstract, Chemical Abstracts, Embase, Index Copernicus, EBSCO, African Index Medicus, JournalSeek, Journal Citation Reports/Science Edition, Directory of Open Access Journals (DOAJ), African Journal Online, Bioline International, Open-J-Gate and Pharmacy Abstracts
\end{abstract}

\section{INTRODUCTION}

Stroke is the second leading cause of death in the world. It is the most serious and deadliest disease of the nervous system. It severely affects the quality of life of patients, and brings a huge economic burden to families as well as the society. Stroke is an acute cerebrovascular 
disease [1]. It is often caused by a sudden rupture of the basilar artery or a local vascular embolization that causes a sharp decrease in blood supply to the brain. It includes ischemic and hemorrhagic strokes. The incidence of ischemic stroke is the highest, accounting for $60 \%$ to $70 \%$ of the total number of strokes [1].

After cerebral ischemia occurs, timely restoration of blood flow in the ischemic area is one of the most effective solutions to reduce brain tissue damage. However, after the ischemic brain tissue restores blood flow, reactive oxygen species (ROS) will be produced in large quantities, which in turn will aggravate nerve cell apoptosis and necrosis [2]. This phenomenon is called cerebral ischemia/reperfusion injury [2]. Clinically, thrombolytics are often used to treat ischemic stroke, but due to their narrow therapeutic time window, the application of thrombolytics is significantly restricted [3]. Therefore, finding new effective therapeutic drugs is of significant clinical importance.

Octreotide (OCT) is a synthetic analog of somatostatin 8 peptide. This product has a similar effect to natural somatostatin, and has a stronger and longer lasting effect than natural somatostatin [4]. OCT works through the somatostatin receptor (SSTR), and OCT has the same functional domain as somatostatin [4,5]. Studies have shown that OCT exerts its pharmacological activity mainly by inhibiting the level of adenylate cyclase, reducing the load of intracellular calcium, and activating protein kinases [6]. Significant results have been achieved in the clinical treatment of acromegaly, endocrine tumors, and severe pancreatitis [7-9]. However, the role of OCT in ischemic stroke has been rarely studied.

Hypoxia/ Reoxygenation (H/R) -induced cerebral infarction model was established to investigate whether octreotide could play an anti-oxidative stress, anti-inflammatory and anti-apoptotic role, and its potential mechanism of action.

\section{EXPERIMENTAL}

\section{Cell culture and treatment}

N2A cells were obtained from the Cell Bank of the Chinese Academy of Sciences (Shanghai, China). The cells were cultivated in Dulbecco's modified Eagle's medium (DMEM; Gibco, Rockville, MD, USA) containing $10 \%$ fetal bovine serum (FBS; Gibco, Rockville, MD, USA), and in a cell incubator containing $5 \% \mathrm{CO}_{2}$ at $37{ }^{\circ} \mathrm{C}$. The N2A cells were cultured in a hypoxic chamber with glucose-free medium for $4 \mathrm{~h}$, and then changed to complete medium and cultured in a normoxic incubator for $24 \mathrm{~h}$ to establish a hypoxia/reoxygenation $(H / R)$ injury model. The cells were divided into 3 groups: control group, $H / R$ group, and H/R + OCT group. The cells in $\mathrm{H} / \mathrm{R}+\mathrm{OCT}$ group were pretreated with OCT (60 $\mathrm{ng} / \mathrm{mL}$ ) before H/R treatment.

\section{Cell counting kit-8 (CCK-8) assay}

The N2A cells were seeded in a 96-well plate. 10 $\mu \mathrm{L}$ of CCK-8 reagent (MCE, Nanjing, China) was added into wells. $2 \mathrm{~h}$ later, the absorbance at 450 $\mathrm{nm}$ was detected using a microplate reader.

\section{Determination of oxidative stress indicators}

In order to assess the level of oxidative stress in N2A cells, the levels of SOD, GSH-Px, CAT, ROS and MDA were determined. The levels of SOD, GSH-Px, CAT, and MDA were also determined using corresponding commercial kits (Beyotime, Shanghai, China).

The level of ROS in N2A cells was measured using DCFH-DA (MCE, Nanjing, China). The N2A cells were incubated with DCFH-DA solution $(5 \mu \mathrm{M})$ in the dark for $30 \mathrm{~min}$ at $37^{\circ} \mathrm{C}$, then harvested using $0.05 \%$ trypsin-EDTA solution and suspended in a fresh medium, and immediately analyzed with flow cytometer.

\section{Measurement of inflammatory cytokines}

Total protein of N2A cells was isolated using cell lysis reagent (Thermo Fisher Scientific, Waltham, MA, USA). The expression of inflammatory cytokines (TNF- $\alpha, \quad \mathrm{IL}-1 \beta, \quad \mathrm{IL}-6, \quad \mathrm{IL}-8)$ was determined using enzyme-linked immunosorbent assay (ELISA) kits (Beyotime, Shanghai, China).

\section{Western blot}

The total protein was extracted using cell lysis reagent (Thermo Fisher Scientific, Waltham, MA, USA). The concentration was measured by the bicinchoninic acid (BCA) method (Pierce, Rockford, IL, USA). The same amount of total protein $(30 \mu \mathrm{g})$ were separated in sodium dodecyl sulphate-polyacrylamide gel electrophoresis (SDS-PAGE) gel and then transferred onto polyvinylidene fluoride (PVDF) membrane (Thermo Fisher Scientific, Waltham, MA, USA). Then the non-specific antigens of the protein were blocked using skimmed milk (5\%). The primary antibodies (Bcl-2, Abcam, Cambridge, MA, USA, Rabbit, 1:1000; Bax, Abcam, Cambridge, MA, USA, Rabbit, 1:1000; TLR4, Abcam, Cambridge, MA, USA, Rabbit, 1:1000; MyD88, Abcam, Cambridge, MA, USA, Rabbit, 
1:1000; NF-kB, Abcam, Cambridge, MA, USA, Rabbit, 1:1000; GAPDH, Abcam, Cambridge, MA, USA, Rabbit, 1:1000) were used to incubate the membranes at $4^{\circ} \mathrm{C}$ overnight, followed by incubation with secondary antibodies for $2 \mathrm{~h}$. Finally, the blots were exposed by Image Lab ${ }^{\mathrm{TM}}$ Software.

\section{Caspase-3/9 activity assay}

The total protein was extracted using cell lysis reagent (Thermo Fisher Scientific, Waltham, MA, USA) and the concentration was measured through the Bicinchoninic acid (BCA) kit according to the instructions of the supplier (Beyotime, Shanghai, China). The expression of Caspase-3 and Caspase-9 was detected using Caspase- 3 activity assay kit and Caspase-9 activity assay kit (Beyotime, Shanghai, China).

\section{Statistical analysis}

Statistical analysis was performed using Statistical Product and Service Solutions (SPSS) 22. 0 software (IBM, Armonk, NY, USA). Data was represented as mean \pm Standard Deviation (SD). Differences between two groups were analyzed by using the Student's t-test. Comparison between multiple groups was done using One-way analysis of variance (ANOVA) test, followed by Post-Hoc Test (Least Significant Difference). $P<0.05$ indicated the significant difference.

\section{RESULTS}

\section{Octreotide (OCT) ameliorated H/R-induced N2A cell injury}

The hypoxia/reoxygenation (H/R) injury model was established, and the N2A cells were treated with different concentrations $(20,40,60,80,100$ $\mathrm{ng} / \mathrm{mL}$ ) of OCT. The viability of N2A cells were detected by CCK-8 assay. H/R treatment significantly reduced the cell viability of N2A. OCT, with a concentration of more than 40 $\mathrm{ng} / \mathrm{mL}$ significantly improve cell viability, and at the concentration of $60 \mathrm{ng} / \mathrm{mL}$, the cell viability reached the highest (Figure 1). So $60 \mathrm{ng} / \mathrm{mL}$ OCT was used for subsequent experiments.

\section{OCT ameliorated H/R-induced oxidative stress of N2A cells}

The activities of SOD, GSH-Px, and CAT were notably reduced after the treatment of $H / R$. However, OCT treatment markedly increased the activities of SOD, GSH-Px, and CAT (Figure 2 A - C). The levels of ROS and MDA were also tested. Compared with the control group, the levels of ROS and MDA in the H/R group were significantly increased. While compared with the H/R group, the levels of ROS and MDA in the $\mathrm{H} / \mathrm{R}+\mathrm{OCT}$ group were significantly reduced (Figure $2 \mathrm{D}$ and $\mathrm{E}$ ). These results suggest that OCT can inhibit H/R-induced oxidative stress in N2A cells.

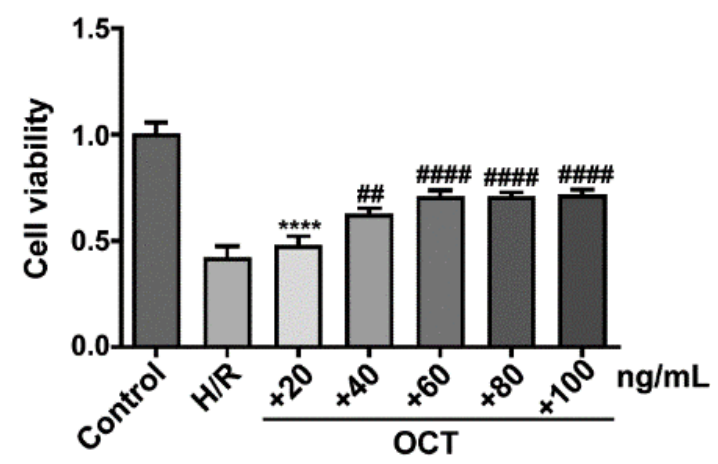

Figure 1: OCT ameliorated H/R-induced N2A cell injury. CCK-8 assay showed the viability of N2A cells. ${ }_{* * * *} P<0.0001$ vs. control, \#p $<0.01$ vs. H/R, \#\#\#p < 0.0001 vs. $H / R, n=3$

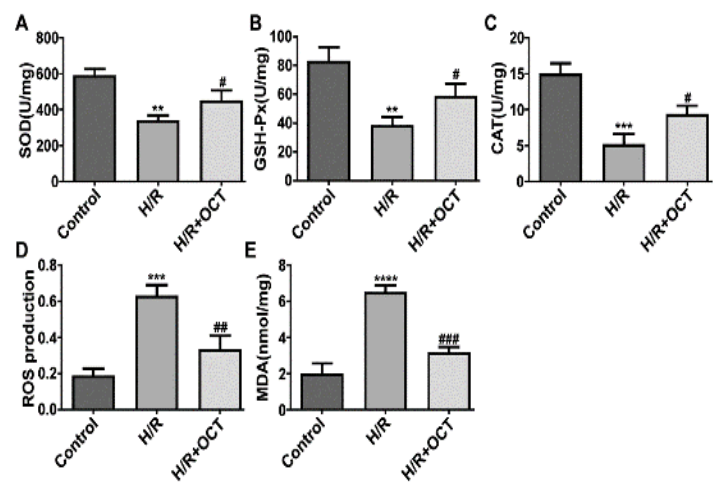

Figure 2: OCT ameliorated $\mathrm{H} / \mathrm{R}$-induced oxidative stress of N2A cells. (A) SOD, (B) GSH-Px, (C) CAT, (D) ROS, and (E) MDA levels in N2A cells were detected. ${ }^{*} P<0.01$ vs. control, ${ }_{* * *} p<0.001$ vs. control, ${ }_{* * * *} p<0.0001$ vs. control, $\# p<0.05$ vs. $\mathrm{H} / \mathrm{R}, \# p<0.01$ vs. $\mathrm{H} / \mathrm{R}$, \#\# 0.0001 vs. $\mathrm{H} / \mathrm{R} ; \mathrm{n}=3$

\section{OCT ameliorated H/R-induced inflammation of $\mathrm{N} 2 \mathrm{~A}$ cells}

In order to assess the level of inflammation in $\mathrm{N} 2 \mathrm{~A}$ cells, the activities of inflammatory cytokines (TNF- $\alpha, \mathrm{IL}-1 \beta, \mathrm{IL}-6, \mathrm{IL}-8$ ) were tested. The level of inflammatory cytokines in the H/R group was significantly higher than that in the control group, but OCT treatment significantly reversed this (Figure 3 A - D). These results indicated that OCT can inhibit H/R-induced inflammation of N2A cells.

Trop J Pharm Res, November 2021; 20(11): 2263 

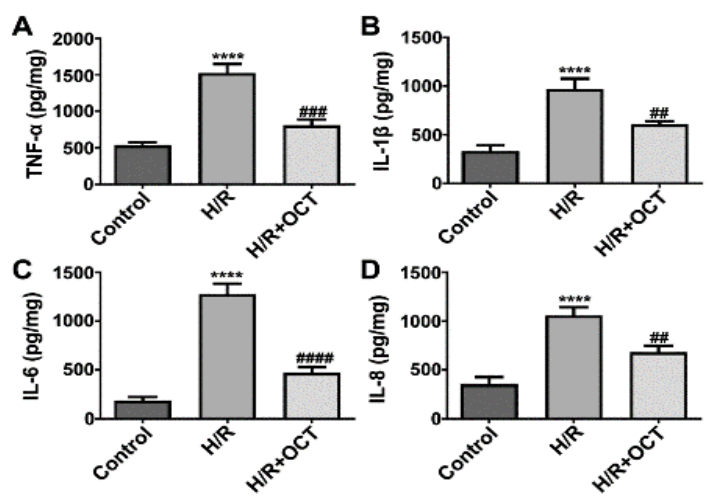

Figure 3. OCT ameliorated $\mathrm{H} / \mathrm{R}$-induced inflammation of N2A cells. (A) TNF- $\alpha$, (B) IL-1 $\beta$, (C) IL- 6 , and (D) IL8 expression in N2A cells was detected. "****” $p<0.0001$ vs. control, "\#” $p<0.01$ vs. H/R, “\#”" $p<0.001$ vs. $H / R$, “\#”\#” $p<0.0001$ vs. H/R, n= 3

\section{OCT ameliorated H/R-induced apoptosis of N2A cells}

Western blot analysis indicated that $\mathrm{H} / \mathrm{R}$ can inhibit the expression of $\mathrm{Bcl}-2$ in N2A cells and induce the expression of Bax. However, OCT treatment increased the expression of $\mathrm{Bcl}-2$ and inhibit the expression of Bax (Figure $4 \mathrm{~A}-\mathrm{C}$ ). In addition, the activities of Caspase- 3 and Caspase- 9 were also determined. Compared with the control group, the levels of Caspase-3 and Caspase-9 in the H/R group were significantly increased. Compared with the H/R group, the levels of Caspase- 3 and Caspase- 9 in the $\mathrm{H} / \mathrm{R}+\mathrm{OCT}$ group were significantly reduced (Figure $4 \mathrm{D}$ and $\mathrm{E}$ ). OCT treatment also reduced the rate of N2A cell apoptosis caused by H/R (Figure $4 \mathrm{~F}$ ). These results showed that OCT can inhibit H/R-induced apoptosis of N2A cells.

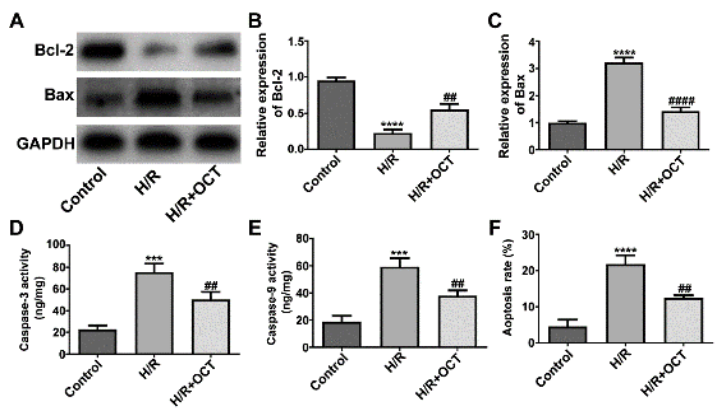

Figure 4. OCT ameliorated $\mathrm{H} / \mathrm{R}$-induced apoptosis of N2A cells. (A) Representative Western blot of Bcl-2 and Bax expression. ( $B$ and $C$ ) Quantification of expression of Bcl-2 and Bax. (D and E) The activities of Caspase- 3 and Caspase- 9 were detected. (F) The apoptosis rate of $\mathrm{N} 2 \mathrm{~A}$ cells was detected by flow cytometry. " "***" $p<0.001$ vs. control, " $* * * * " p<0.0001$ vs. control, “\#” $p<0.01$ vs. H/R, “\#\#” $p<0.0001$ vs. H/R, n $=3$

\section{OCT inhibited the TLR4/MyD88/NF-kB signaling pathway}

The TLR4/MyD88/NF-kB pathway plays a very important role in regulating oxidative stress, inflammation and apoptosis, so we examined the expression of TLR4, MyD88 and NF-KB in N2A cells through Western blot (Figure 5 A). Compared with the control group, the expression of TLR4, MyD88 and NF-KB in the H/R group was significantly increased. However, the OCT treatment inhibited the expression of these proteins (Figure 5 B - D).

A

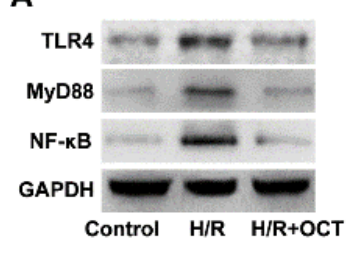

B

C

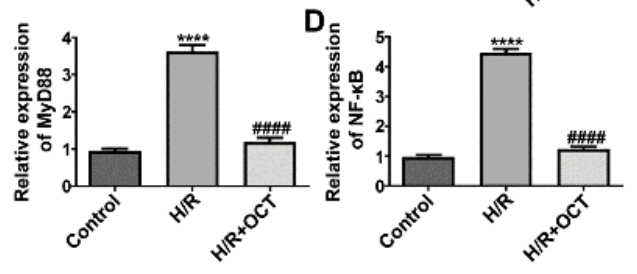

Figure 5. OCT inhibited the TLR4/MyD88/NF-KB signaling pathway. (A) Representative Western blot of TLR4, MyD88 and NF-KB expression. (B D) Quantification of expression of TLR4, MyD88 and NFKB. "stotu”" $p<0.0001$ vs. control, "\#\#" $p<0.0001$ vs. $H / R, n=3$

\section{DISCUSSION}

The study revealed the protective role of OCT in ischemia stroke. It also revealed that OCT inhibited H/R-induced oxidative stress, inflammation and apoptosis. This protective effect was achieved at least in part by inhibiting the TLR4/MyD88/NF-KB signaling pathway.

Ischemic stroke is mainly caused by local cerebrovascular obstruction, which is common in the middle cerebral artery with atherosclerosis and thrombosis. This is a pathophysiological process involving multiple complex mechanisms such as cytotoxicity, oxidative stress damage, inflammation, and apoptosis. After acute injury, there is secondary injury, first tissue energy metabolism disorder, then $\mathrm{Na}^{+}-\mathrm{K}^{+}$-ATPase inactivation and ion imbalance, and finally tissue edema. At the same time, excitotoxicity also begins immediately after central nervous system injury, and is mainly manifested as increased release of excitatory amino acids (such as glutamate) and decreased re-uptake, leading to 
excessive activation of ionotropic glutamate receptors. The activation of glutamate receptors causes lethal large amounts of $\mathrm{Ca}^{2+}$ to enter the cell to activate protein kinases, nucleases and other enzymes to generate large amounts of free radicals to poison the neurons $[10,11]$. With the occurrence of the above events, the following pathophysiological processes have occurred successively, such as inflammation, oxidative stress, and endoplasmic reticulum stress [12,13]. The activated microglial cells release proinflammatory cytokines to attract macrophages and neutrophils chemotaxis to the central nervous system. All cells that release proinflammatory cytokines, reactive oxygen species and reactive nitrogen species are highly cytotoxic to neurons [14]. In addition, NADPH oxidase is activated to form ROS and reduces the effect of antioxidants (such as SOD), and hydrogen peroxide can promote oxidative stress. As more and more unfolded or misfolded proteins accumulate, ER response signaling pathways and downstream apoptotic transcription factors such as CCAAT-enhancer-binding protein homologous protein (CHOP) and activating transcription factor 4 (ATF4) will be activated. Inflammatory reaction, oxidative/nitride stress and endoplasmic reticulum stress occur simultaneously and promote each other [13].

Toll-like receptors (TLRs) are a family of receptors that mediate innate immunity. As a key transmembrane protein that triggers inflammatory responses, they participate in the regulation of immune inflammatory responses and are considered to be the main body that manages immune and inflammatory responses [15]. TLRs initiate immune responses mainly through specific recognition of pathogen-related molecular patterns (PAMPs) and damage-related molecular patterns (DAMPs), which not only constitute an important part of the innate immune system, but also play an important role in acquired immune response signals. The study found that TLRs have two classic signal transduction pathways, including Myd88dependent signaling pathway mediated by Myd88 and Myd88-independent signaling pathway mediated by TRIF. MyD88 mediates the signal transduction of a variety of TLRs including TLR4, NF-KB and MAPKs, and produces a variety of inflammatory mediators. TLR4 can produce TNF-a and IL-1 through MyD88 and TRIF signaling pathway. DAMPs released by neurons after ischemia-reperfusion injury can activate the TLR4/MyD88/NF-KB signaling pathway of surrounding microglia, promote the expression of inflammatory mediators, and promote neuronal apoptosis. In recent years, studies have found that regulating the NF-kB pathway mediated by TLR can alleviate ischemic damage to various organs (including the brain, heart, kidney) [16-18].

\section{CONCLUSION}

These results indicate that OCT inhibits H/Rinduced oxidative stress, inflammatory responses, and apoptosis of N2A cells by inhibiting the TLR4/MyD88/NF-kB signaling pathway. Thus, the findings provide new insights for the treatment of cerebral infarction.

\section{DECLARATIONS}

\section{Conflict of Interest}

No conflict of interest associated with this work.

\section{Contribution of Authors}

The authors declare that this work was done by the authors named in this article and all liabilities pertaining to claims relating to the content of this article will be borne by them.

\section{Open Access}

This is an Open Access article that uses a funding model which does not charge readers or their institutions for access and distributed under the terms of the Creative Commons Attribution License (http://creativecommons.org/licenses/by/ 4.0) and the Budapest Open Access Initiative (http://www.budapestopenaccessinitiative.org/rea d), which permit unrestricted use, distribution, and reproduction in any medium, provided the original work is properly credited.

\section{REFERENCES}

1. Mozaffarian D, Benjamin EJ, Go AS, Arnett DK, Blaha MJ, Cushman M, Das SR, de Ferranti S, Despres JP, Fullerton $\mathrm{HJ}$, et al. Heart Disease and Stroke Statistics2016 Update: A Report From the American Heart Association. Circulation 2016; 133(4): e38-e360.

2. Chen CJ, Cheng FC, Liao SL, Chen WY, Lin NN, Kuo JS. Effects of naloxone on lactate, pyruvate metabolism and antioxidant enzyme activity in rat cerebral ischemia/reperfusion. Neurosci Lett 2000; 287(2): 113116.

3. Khandelwal $P$, Yavagal DR, Sacco RL. Acute Ischemic Stroke Intervention. J Am Coll Cardiol 2016; 67(22): 2631-2644.

4. Scarpignato C, Pelosini I. Somatostatin analogs for cancer treatment and diagnosis: an overview. Chemotherapy 2001; 47 Suppl 2: 1-29. 
5. Jenkins SA, Kynaston HG, Davies ND, Baxter JN, Nott $D M$. Somatostatin analogs in oncology: a look to the future. Chemotherapy 2001; 47 Suppl 2: 162-196.

6. Nakayama $R$, Yano $T$, Ushijima $K$, Abe E, Terasaki $H$. Effects of dantrolene on extracellular glutamate concentration and neuronal death in the rat hippocampal CA1 region subjected to transient ischemia. Anesthesiology 2002; 96(3): 705-710.

7. Baldelli $R$, Colao $A$, Razzore $P$, Jaffrain-Rea $M L$, Marzullo $P$, Ciccarelli E, Ferretti E, Ferone $D$, Gaia $D$, Camanni $F$, et al. Two-year follow-up of acromegalic patients treated with slow release lanreotide $(30 \mathrm{mg}) . \mathrm{J}$ Clin Endocrinol Metab 2000; 85(11): 4099-4103.

8. Rockey DC. Pharmacologic therapy for gastrointestinal bleeding due to portal hypertension and esophageal varices. Curr Gastroenterol Rep 2006; 8(1): 7-13.

9. Ramos-De LMA, Sarr MG. Somatostatin analogues in the prevention of pancreas-related complications after pancreatic resection. J Hepatobiliary Pancreat Surg 2006; 13(3): 190-193.

10. Hazell AS. Excitotoxic mechanisms in stroke: an update of concepts and treatment strategies. Neurochem Int 2007; 50(7-8): 941-953.

11. Obrenovitch TP, Urenjak J. Altered glutamatergic transmission in neurological disorders: from high extracellular glutamate to excessive synaptic efficacy. Prog Neurobiol 1997; 51(1): 39-87.

12. Lakhan SE, Kirchgessner A, Hofer M. Inflammatory mechanisms in ischemic stroke: therapeutic approaches. J Transl Med 2009; 7: 97.
13. Nakka VP, Prakash-Babu P, Vemuganti R. Crosstalk Between Endoplasmic Reticulum Stress, Oxidative Stress, and Autophagy: Potential Therapeutic Targets for Acute CNS Injuries. Mol Neurobiol 2016; 53(1): 532544.

14. Manzanero S, Santro T, Arumugam TV. Neuronal oxidative stress in acute ischemic stroke: sources and contribution to cell injury. Neurochem Int 2013; 62(5): 712-718.

15. Eklind S, Mallard C, Leverin AL, Gilland E, Blomgren K, Mattsby-Baltzer I, Hagberg $H$. Bacterial endotoxin sensitizes the immature brain to hypoxic--ischaemic injury. Eur J Neurosci 2001; 13(6): 1101-1106.

16. Liu FY, Cai J, Wang C, Ruan W, Guan GP, Pan HZ, Li $J R$, Qian C, Chen JS, Wang L, et al. Fluoxetine attenuates neuroinflammation in early brain injury after subarachnoid hemorrhage: a possible role for the regulation of TLR4/MyD88/NF-kappaB signaling pathway. J Neuroinflammation 2018; 15(1): 347.

17. Su Q, Lv X, Sun $Y, Y e Z$, Kong B, Qin Z. Role of TLR4/MyD88/NF-kappaB signaling pathway in coronary microembolization-induced myocardial injury prevented and treated with nicorandil. Biomed Pharmacother 2018; 106: 776-784.

18. Jin $Y H$, Li ZT, Chen $H$, Jiang $X Q$, Zhang $Y Y, W u$ F. Effect of dexmedetomidine on kidney injury in sepsis rats through TLR4/MyD88/NF-kappaB/iNOS signaling pathway. Eur Rev Med Pharmacol Sci 2019; 23(11): 5020-5025. 